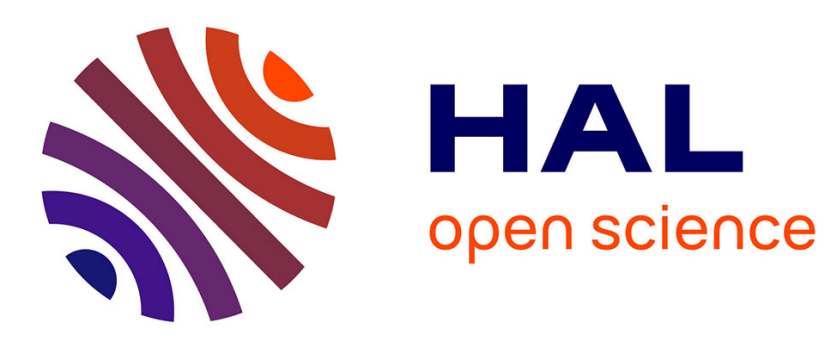

\title{
Microstructural Investigation of Co-rolled Nanocrystalline Stainless Steel Sheets
}

Delphine Retraint, Zakaria Quadir, Wanqiang Xu, Laurent Waltz, Michael Ferry

\section{- To cite this version:}

Delphine Retraint, Zakaria Quadir, Wanqiang Xu, Laurent Waltz, Michael Ferry. Microstructural Investigation of Co-rolled Nanocrystalline Stainless Steel Sheets. Materials Science Forum, 2011, 702-703, pp.127-130. 10.4028/www.scientific.net/MSF.702-703.127 . hal-00855440

\author{
HAL Id: hal-00855440 \\ https://hal.science/hal-00855440
}

Submitted on 29 Aug 2013

HAL is a multi-disciplinary open access archive for the deposit and dissemination of scientific research documents, whether they are published or not. The documents may come from teaching and research institutions in France or abroad, or from public or private research centers.
L'archive ouverte pluridisciplinaire HAL, est destinée au dépôt et à la diffusion de documents scientifiques de niveau recherche, publiés ou non, émanant des établissements d'enseignement et de recherche français ou étrangers, des laboratoires publics ou privés. 


\title{
Microstructural Investigation of Co-rolled Nanocrystalline Stainless Steel Sheets
}

\author{
Delphine Retraint, ${ }^{1, \mathrm{a}}$ Zakaria Quadir, ${ }^{2,3, \mathrm{~b}}$ Wanqiang $\mathrm{Xu},{ }^{3, \mathrm{c}}$ \\ Laurent Waltz ${ }^{4, d}$ and Michael Ferry ${ }^{3, e}$ \\ ${ }^{1}$ Charles Delaunay Institute, University of Technology of Troyes, Troyes, France \\ ${ }^{2}$ Electron Microscope Unit, University of New South Wales, Sydney, Australia \\ ${ }^{3}$ School of Materials Science and Engineering, University of New South Wales, Sydney, Australia \\ ${ }^{4}$ Laboratoire de Mécanique et Génie Civil (LMGC) de Montpellier, France \\ a delphine.retraint@utt.fr, ${ }^{b}$ mzquadir@unsw.edu.au, ${ }^{c}$ wxu@unsw.edu.au, \\ 'Laurent.Waltz@univ-montp2.fr, ${ }^{\mathrm{e}}$ m.ferry@unsw.edu.au
}

Keywords: SMAT, Roll-bonding, Grain refinement, Nanocrystallized material, Multilayered structure, Electron backscatter diffraction (EBSD)

\begin{abstract}
It is possible to produce a nanocrystalline, multilayered composite structure with enhanced mechanical properties by assembling three 316L surface nanostructured stainless steel plates by roll bonding. The Surface Mechanical Attrition Treatment (SMAT) was first used to generate nanocrystalline layers on the elementary plates so that their mechanical properties were improved. They were then assembled through co-rolling. A composite structure of nanocrystalline layers of high strength alternating with more ductile layers was obtained to achieve both high strength and ductility. Microscopy observations and EBSD measurements were carried out and the bonding interfaces were analysed in detail to explore the mechanisms involved during the SMAT/Co-rolling duplex process.
\end{abstract}

\section{Introduction}

The 316L austenitic stainless steel is commonly used in the food, chemical or petrochemical industries. It shows excellent anticorrosion properties but poor mechanical strength. This reason limits the widespread application of this alloy. One potential solution to this problem is to apply a mechanical surface treatment to improve its mechanical strength without affecting its anti-corrosive properties. Several studies relating to surface nanocrystallization by severe plastic deformation have shown that the recently developed Surface Mechanical Attrition Treatment (SMAT) refines the average grain size down to the nanometer scale in the top surface of the treated metallic specimens, while the average grain size of the bulk sample remains in the micrometer range [1-5]. This treatment leads to a considerable enhancement of the yield and ultimate strengths. However, SMAT also has a detrimental effect on the ductility properties of the material [6].

In the present work, a method is presented combining the SMAT and the co-rolling process for developing a semi-massive multilayer bulk structure with improved strength and acceptable ductility. To characterize this new material, conventional mechanical testing and nanoindentation experiments were carried out [6]. In this complementary study, a microstructural analysis of the SMATed and hot co-rolled laminate structures was investigated. Optical microscopy (OM) and Scanning Electron Microscopy (SEM) coupled with electron backscatter diffraction (EBSD) were used to understand the roll bonding and strengthening mechanisms.

\section{Experimental procedures}

Performing SMAT: The materials used in this investigation were commercial grade 316L austenitic stainless steel plates of dimensions $120 \times 120 \times 1 \mathrm{~mm}$ and chemical composition (wt.\%) $0.025 \mathrm{C}, 0.38$ $\mathrm{Si}, 1.33 \mathrm{Mn}, 0.027 \mathrm{P}, 0.002 \mathrm{~S}, 16.70 \mathrm{Cr}, 2.09 \mathrm{Mo}, 10.20 \mathrm{Ni}, 0.030 \mathrm{~N}, 0.40 \mathrm{Cu}$ and $0.07 \mathrm{Co}$. The initial 
microstructure of the as-received material was characterised and found to exhibit and equiaxed grain structure of size 40-120 $\mu \mathrm{m}$. The surface nanocrystallization of the stainless steel sheets was achieved using ultrasonic-assisted SMAT in air. The other SMAT parameters such as the temperature, time, shot ball diameter and vibration rates are $27{ }^{\circ} \mathrm{C}, 30$ minutes, $3 \mathrm{~mm}$ and $20 \mathrm{kHz}$, respectively. The details of the process are described by Lu et al. [5].

Co-Rolling of SMATed sheets: The co-rolling process consisted of hot rolling of three nanocrystallized SMATed sheets, as illustrated in Fig. 1.

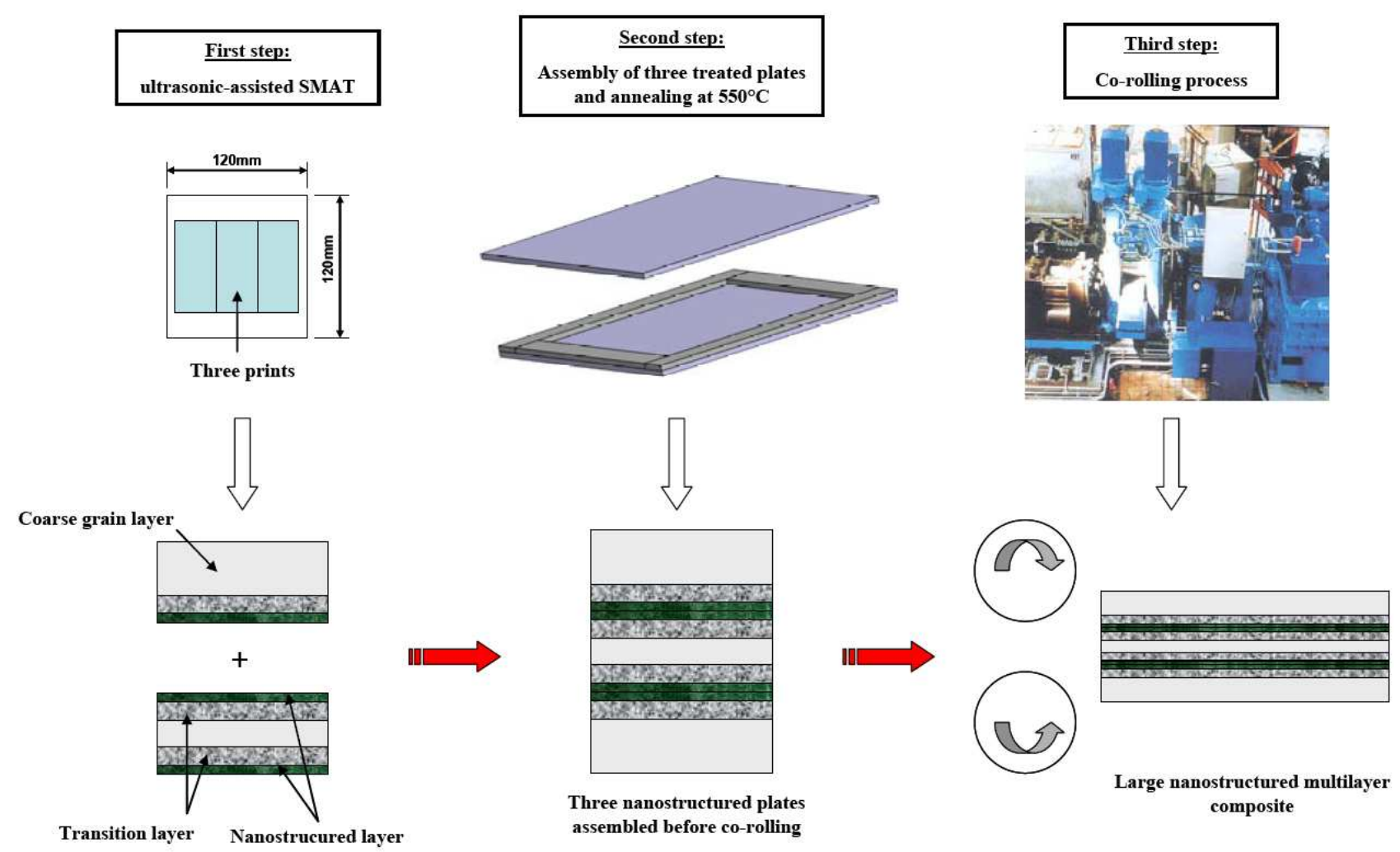

Fig. 1: Global view of the duplex process combining the SMAT and the co-rolling process of stainless steel samples.

At the first step, each 316L stainless steel plate was prepared by the SMAT process. For the middle plate, SMAT was carried out on both surfaces and, for the outer plates, it was carried out in the inner surface. The plates were stacked and assembled in a co-rolling sheath, which was especially designed for this application, as shown in Fig. 1. Then the rig was heated to $550{ }^{\circ} \mathrm{C}$ for $90 \mathrm{~min}$ and rolled to $55 \%$ reduction in thickness without lubrication in two passes. The co-rolling was carried out on a semi-industrial STANAT reversible quarto rolling mill, operating under a load of $\sim 3500 \mathrm{kN}$. The low magnification microstructural study of the co-rolled samples was characterized using optical microscopy. For high magnification studies, a JEOL 7001 scanning electron microscope (FEG-SEM), equipped with a TSL electron backscatter diffraction (EBSD) system, was used. The EBSD analysis was carried out at $15 \mathrm{kV}$ using various step sizes, down to $50 \mathrm{~nm}$.

\section{Results and discussion}

Figure 2 shows an optical micrograph of the cross-section (plane defined by the rolling and normal directions) of the co-rolled sample. The three layers composing the laminates are clearly distinguishable in Fig. 2a. The elongated fibrous structures in the middle of the sheets were formed during rolling. The two bonding interfaces between the sheets appeared as dark lines in Fig. 2a. The magnified image of the bonding region, in Fig $2 b$, shows that at some points the metal came into 
contact to create a good bonding while in other areas there are gaps. These gaps are filled with oxide clusters. An analysis of these oxides was carried out and reported in ref 7 where it was found that these are primarily composed of hematite, magnetite and other complex oxides.

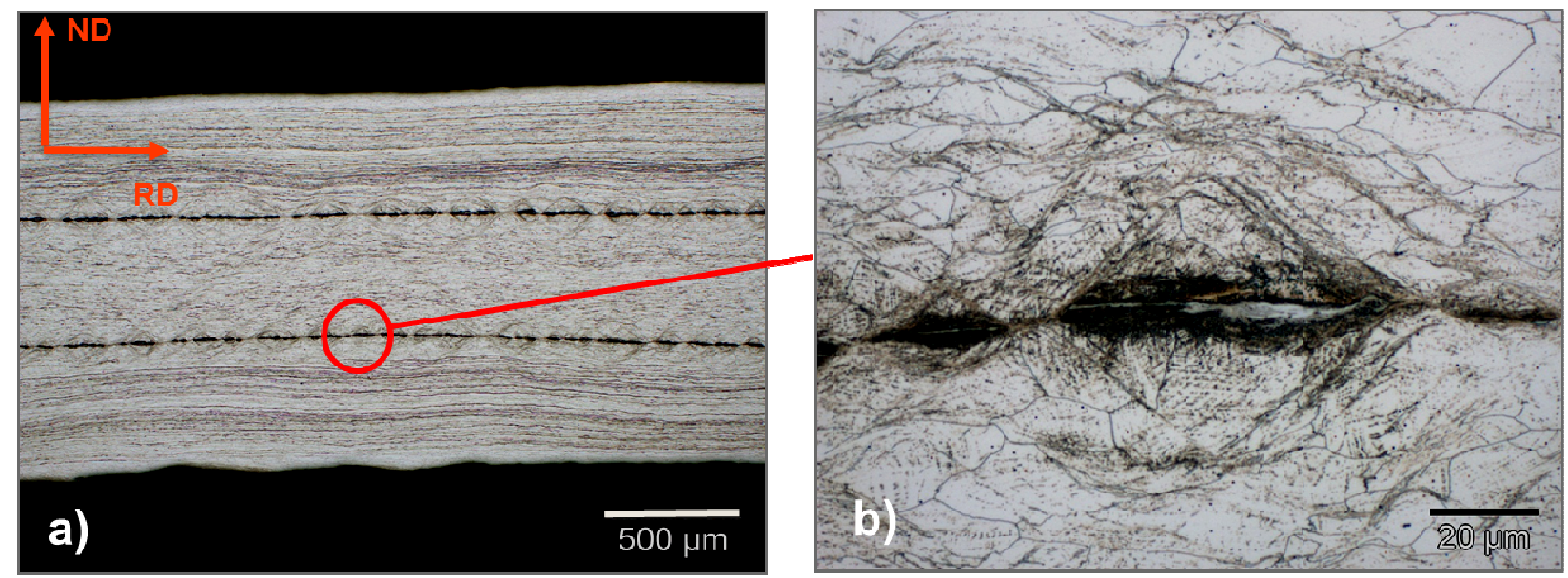

Fig. 2: a) Optical micrograph of the cross-section of a stainless steel sample after SMAT processing and co-rolling at $550^{\circ} \mathrm{C}$. b) Magnified image of the oxide islets present at the interface.

Fig. 3 shows an EBSD inverse pole figure orientation map of an area across the bonding interface. This map was one-step smoothed, by which one low indexed neighbor of a good indexed point was turned into the same orientation. This map shows a low indexed interface at the middle. This low indexing is possibly due to the thick oxide layer. At the point of metal-metal contact a shear band can be seen from the finer fragmented structures along the line of operation, as arrowed by A and B markers. This kind of shear banding assisted bonding was widespread in this sample, as can be seen from the optical images in Figs 1a and b. Measuring the mechanical properties of the oxides is difficult because of their limited volume and non-homogenous structures. However, from the nature of metal flow, that moved around the oxide debris, it is obvious that they are harder than the metal. These results show that to establish a good bonding the interface needs to remain clean and free from oxide during the rolling. This is rather difficult when the rolling was carried out at $550{ }^{\circ} \mathrm{C}$. An alternative approach for enhancing the bonding is to control the nature of the shear banding since it is clear that they create channels for the base metal to come in contact by puncturing the oxide layer. This was found by Quadir et al. [8] whereby shear banding operates through the oxide debris at the interface and creates bonding in commercially pure aluminum alloys during roll bonding at higher temperatures. In order to control the nature and frequency of the shear banding, the mechanical properties and dimensions of the base metals and the oxide are considered as important factors. As it also shown by Quadir et al. [9], the larger the difference in hardness, the more likely that shear bands will form across the interface. The other factors such as temperature, Taylor hardening (texture) and grain size also have strong influence on shear banding [9]. Therefore, a good control of the parameter may enhance the bond strength by fragmenting the oxide debris into small particles.

Near the bonding interface there is also a high density of high angle boundaries in the deformation microstructure. This was further confirmed by a higher resolution EBSD mapping. These areas were fragmented by the SMAT process to $200-300 \mathrm{~nm}$ and the data was further clarified by TEM investigations. The regions away from the interface contain elongated grain structures with interior substructures. These are typical rolling substructures created during the co-rolling process. 


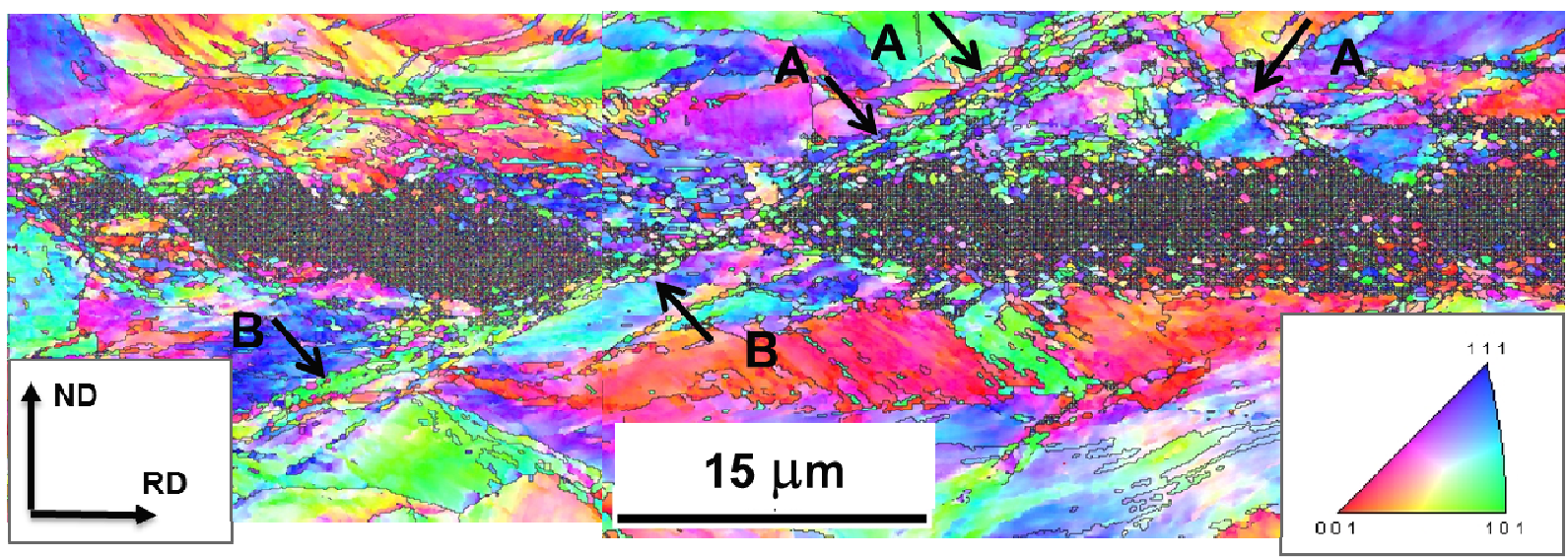

Fig. 3: EBSD orientation map of the region near the interface showing shear bands around (arrows A) and between (arrows B) two oxide islets.

\section{Conclusions}

In the present study, the microstructure of a multilayered composite structure produced by SMAT and co-rolling of $316 \mathrm{~L}$ austenitic stainless steel was investigated. Optical and electron microscopy observations have shown that the bonding interface contains discontinuous oxide debris and the bonding was primarily achieved by the operation of shear bands across them.

Acknowledgements: We thank the Champagne-Ardenne Research Council (France) and European Funds for Regional Development (FEDER) for the provision of research (Nanosurf project) and equipment grant which made this work possible. D. Retraint especially thanks Champagne-Ardenne region for allocating the travel and accommodation funds to undertake this study at the University of New South Wales.

\section{References}

[1] N.R. Tao, M.L. Sui, J. Lu, and K. Lu: Surface nanocrystallization of iron induced by ultrasonic shot peening, NanoStruc. Mater. 11 (1999) 443-440.

[2] G. Liu, J. Lu, and K. Lu, Surface nanocrystallization of 316L stainless steel induced by ultrasonic shot peening, Mater. Sci. Eng. A 286 (2000) 91-95.

[3] T. Roland, D. Retraint, J. Lu, K. Lu, Enhanced mechanical behavior of a nanocristallised stainless steel and its thermal stability, Mater. Sci. Eng. A445-446 (2007) 281-288.

[4] X.H. Chen, J. Lu, L. Lu, K. Lu, Tensile properties of a nanocrystalline 316 austenitic stainless steel, Scripta Mater. 52 (2005) 1039-1044.

[5] K. Lu, J. Lu, Surface nanocrystallization (SNC) of materials and its Effects on Mechanical Behaviour, Encyclopedia of Comprehensive Structural Integrity (CSI) 8 (2002) 1-35.

[6] L. Waltz, D. Retraint, A. Roos, P. Olier, Combination of surface nanocrystallization and co-rolling: Creating multilayer nanocristalline composites, Scripta Mater 60 (2009) 21-24.

[7] L. Waltz, D. Retraint, A. Roos, C. Garnier, P. Olier, Effect of interfacial oxidation during the duplex process combining surface nanocrystallisation and co-rolling, Surface \& Coatings Technology 205 (2011) 4608-4613.

[8] M.Z. Quadir, A. Wolz, M. Hoffman, M. Ferry, Influence of processing parameters on the bond toughness of roll-bonded aluminium strip, Scripta Mater. 52 (2005) 1039-1044.

[9] M.Z. Quadir, M. Ferry, O. Al-Buhamad, P.R. Munroe, Shear banding and recrystallization texture development in a multi-layered $\mathrm{Al}$ ally sheet produced by accumulative roll bonding, Acta Mater. 57 (2009) 29-40. 